DOI: $10.17805 /$ zpu.2020.2.8

\title{
Практики ограничения использования гаджетов в образовательных организациях
}

\author{
А. С. Тимощук \\ ВЛАДИМИРСКИЙ ЮРИДИЧЕСКИЙ ИНСТИТУТ ФСИН
}

Цифровизация и медиатизация имеют двоякий эффект. Они усиливают включенность, повышают событийность, ускоряют процессуальность. С другой стороны, дигитальные технологии предоставляют беспрецедентные возможности по анонимизации зла и манипуляции общественным сознанием. Статья посвящена проблеме использования учащимися гаджетов во время нахождения в образовательных учреждениях России.

Рассматривается судебная практика в отношении курсантов ведомственных вузов, где ответчиком выступает образовательная организация, истцом - отчисленный обучающийся, а в деле фигурируют действия, связанные с использованием мобильного устройства.

Ключевые слова: цифровое общество; информационная безопасность; ИКТ-компетенция; информатизация; дигитализация образования; гаджет-аддикция; джаммер; свобода отключения; цифровая тишина; суверенная когниция

\section{ВВЕАЕНИЕ}

$\mathbf{Q}$ ся наша жизнь сегодня вписана в цивилизационный темп догоняющей модернизации. Медийность, информационный бум, интернет вещей и скорость оказывают сильное и не всегда положительное воздействие на сознание и поведение молодежи, порой порождая неадекватное восприятие реальности, злоупотребление электронными устройствами (Тимощук, 2018). Увеличение суммарного времени использования электронных посредников и когнитивная зависимость от гаджетов, которые мы наблюдаем в последние годы, имеют неоднозначное влияние на процессы социализации и психологическую устойчивость.

Информатизация общества приносит самые разные как положительные, так и негативные последствия для общества. Благотворный эффект глобальной коммуникации и оперативного доступа к знаниям хорошо описан. Почему сегодня образовательные организации устанавливают рамки использования мобильных коммуникаторов Аля обучающихся? Эта тема особенно важна в связи с тем, что обучающиеся часто жалуются на запрет использования мобильных устройств с выходом в Интернет, усматривая в этом ограничение своего права на информацию. Студенты нового поколения next (x, y, z, миллениалы) любят пускаться в рассуждения о том, что в российском законодательстве нет прямых указаний на запрет пользования мобильными телефонами и другими подобными устройствами.

Гаджет-аддикция характеризуется удовлетворенностью при нахождении в контакте с устройством и невозможностью контролировать время и место его использования; ощущением пустоты при лишении доступа к нему, готовностью на малую ложь, чтобы защитить свое право пользования во время учебы или работы; снижением волевой функции личности (Николаева, Волкова, 2013).

Поскольку гаджеты многофункциональны, то конкретный объект зависимости трудно актуализировать. СМС, просматривание контента, социальные сети, музыка, игры, звонки - одна или несколько функций, их чередование или одновременное использование - все это делает из смартфона, флагмана всех гаджетов, незаменимую вещь, которую нужно взять на необитаемый остров. Он - первый, кого касаются утром, и последний, кому говорят «спокойной ночи». 
Учителям и преподавателям необходимо постоянно создавать аргументы для того, чтобы обосновывать обучающимся необходимость ограничения использования различных электронных устройств.

Здесь будет сформулирована идея, согласно которой регулирование использования гаджетов в образовательной организации не является покушением на личную свободу, и приведены примеры, почему это порой необходимо. Такого рода разъяснительную работу с обучающимися нужно проводить постоянно, излагая концепцию сложного технологического общества, где свобода дичности дополняется корпоративной необходимостью. Почему же сегодня в некоторых организациях руководители выпускают приказы о запрете пользования мобильными девайсами?

Цель исследования - рассмотреть практики запретов использования мобильных устройств в образовательных организациях России.

\section{СВОБОАА ОТКАЮЧЕНИЯ}

Вето на мобильные устройства преимущественно можно встретить в режимных организациях, на автозаправках, нефтехимических заводах, на предприятиях с непрерывными производственными линиями, в салонах самолетов, а также в некоторых медицинских и образовательных учреждениях. Где-то это обусловлено исключением генераций помех и воздействий на электронное оборудование; какие-то руководители стремятся не допустить нарушения рабочего процесса; кто-то мотивирует свое решение защитой интересов корпорации, предотвращением нарушения трудовой дисциплины. Часто ограничение использования персональных электронных устройств практикуется в органах госбезопасности, армии. Минобороны последовательно ужесточает требования к пользованию мобильными устройствами для военнослужащих, запрещая телефоны с камерами, не разрешая пользоваться социальными сетями и выкладывать личную информацию и фото, ограничивая пользование мобильной связью до звонков в выходные под присмотром офицера, возбраняя пользоваться социальными сетями после демобилизации в течение пяти лет.

Побудительные причины образовательных организаций особенные. Самая главная - звонки, сообщения и интернет-контент отвлекают учеников от прямых обязанностей. Социально-психологические аспекты зависимости молодежи от виртуальной среды вызывают тревогу у педагогов и психологов (Бозаджиев, 2018; Викторова, 2017; Хатмуллина, 2019). Психика молодого человека находится в процессе формирования. Привлекательное сочетание реального и воображаемого содержания может стать серьезной проблемой для недоразвитой нервной системы и вызвать смещение ценностей, вытеснение обязанностей, поведенческие зависимости. Аддиктивный механизм сложен и индивидуален, но естественное административное решение - это депривация переменного состава организации от модных девайсов.

Функции Интернета весьма разнообразны, он может давать информацию, а также развлекать. Разграничение между двумя модусами составляет трудность для образовательной организации. Чтобы избежать споров, в каких целях использовался мобильный телефон, его проще запретить.

Вторая мотивировка, характерная для школьных (и дошкольных) образовательных организаций: кража / потеря / порча мобильных устройств несовершеннолетних провоцируют конфликты в образовательной организации. Запрет в данном случае не исключает возможность урона, если устройство не сдается на проходной, но снижает риск материальных потерь и других неблагоприятных последствий. 
И наконец, в ряде ведомственных образовательных организаций, главным образом высшего образования, в процессе обучения осуществляется допуск к документам для служебного пользования, имеющим гриф «Секретно» (например, личные дела подследственных, ведомственные приказы в оперативно-розыскной деятельности), к секретным документам, что также накладывает ограничения на пользование персональными электронными устройствами.

Разберем примеры из современной практики. Школы давно сталкиваются с проблемой ограничения мобильной связи и имеют обширный опыт в данном вопросе. Аля успешной работы школьников во время занятий необходимы тишина и внимание, которые нарушают мобильные устройства.

Спонтанные и самочинные попытки педагогов защитить процесс обучения и отобрать у школьника силой телефон и отдать его после занятия или удерживать до прихода родителей не всегда эффективны и встречают сопротивление как незаконные. 3десь нет корыстного мотива, однако есть риск наступления неблагоприятных последствий со стороны родителей в случае неумышленной поломки телефона.

Основной цивилизованной формой воздействия остается моральное воздействие: учеников просят отключить устройства или перевести на беззвучный режим.

Классный руководитель может проинформировать родителей о чрезмерном использовании детьми сотовых телефонов, рассказать об исследованиях влияния на здоровье растущего организма мобильных устройств.

Этот способ не всегда действенный, поэтому отдельные образовательные организации идут по пути выработки положения школы и выпуска специального приказа директора школы, где прописывают требования по отключению звука на мобильных телефонах при входе в школу и полном отключении на время занятия. Администрация школы может димитировать виды устройств. Например, разрешить приносить только простые телефоны без интернет-модуля, фото- и видеокамеры. Обучающийся может только во время перемены принять звонок, СМС и ответить. В этом случае иные коммуникаторы, а именно смартфоны, айфоны и планшеты, будут под запретом.

Отдельную сложность представляют «умные часы» и «смарт-браслеты», наручные устройства повышенной функциональности. Они способны собирать информацию с помощью внешних или встроенных сенсоров, выполнять функции голосового коммуникатора, удаленного слежения, прослушивания звука в окружении. Спорный аспект использования таких устройств в образовательных институтах - это возможность сбора личной информации других лиц без их ведома, что затрагивает их законные интересы и может быть оспорено в судебном порядке. При определенном апгрейде такие часы могу быть дополнены идеальной парой для списывания на экзамене - очками со скрытой видеокамерой и передатчиком. Поэтому использование смарт-браслетов на экзамене запрещается.

Рособрнадзор с 2018 г. объявил правила допуска в помещение для сдачи экзамена: перед тем как войти в класс и получить билет, ученику предстоит пройти через рамку металлоискателя. Помимо традиционных шпаргалок, не допускаются все персональные устройства, которые могут повлиять на самостоятельность ответов: смартфоны (мобильные телефоны), smart-часы (часофоны), поддерживающие IOS, Android или Windows-приложения; любые коммуникаторы; калькуляторы с функциями программирования, хранения массивов данных и их передачи по беспроводной связи; портативные переводчики; фотоаппараты; тр3-плееры; планшеты. Объявлены санкции: 
«Изъятие любого из вышеперечисленных предметов влечет за собой оформление протокола. Ученик, попавшийся на таком проступке, тут же удаляется из аудитории, а результаты его экзамена аннулируются. Кроме того, нарушитель лишается возможности пересдавать ЕГЭ в текущем году» 1 .

Комиссии по ЕГЭ обладают бо́льшими ресурсами и полномочиями, нежели школы в их повседневной практике, где проконтролировать, соблюдают ли учащиеся требование по ограничению пользования индивидуальными смарт-устройствами, трудно. Аля установки арочного металлодетектора школе необходимо получить санитарноэпидемиологическое заключение о его безопасности и обучить персонал, что реализуемо, вероятно, только в крупных федеральных центрах.

Сразу стоит отметить, что педагог и административный персонал не имеют полномочий по совершению такого процессуального действия, как обыск или принудительное обследование тела, одежды и сопутствующих вещей в целях отыскания и изъятия определенных предметов. Процедура досмотра внешне похожа на обыск, разница лишь в производстве. Обыск проводится в рамках уголовного процесса по уголовному делу, а досмотр - в рамках производства по делам об административных правонарушениях. Таким образом, сотрудники образовательной организации не имеют права проводить ни обыск, ни досмотр. Исключение составляют ведомственные вузы, где командный состав имеет право на досмотр дичных вещей курсантов по внутренним приказам, которые доводятся до обучающихся, для предотвращения совершения дисциплинарных проступков.

Отдельные случаи составляют обучающиеся с особым статусом - военнослужащие в расположении учебной части, курсанты. В отношении их на основании нормативных правовых актов, регламентирующих прохождение службы, могут быть применены меры обеспечения производства по материалам о дисциплинарном проступке, включающие личный досмотр, досмотр вещей, изъятие вещей и документов.

Помимо административного досмотра и уголовного обыска, существуют особые процедуры в рамках гражданских взаимоотношений: предполетный и послеполетный досмотры (Воздушный кодекс Российской Федерации 2018 г. ${ }^{2}$ ), доступ в здание вокзала, метро (Указ Президента РФ «О создании комплексной системы обеспечения безопасности на транспорте» 2019 г. $\left.{ }^{3}\right)$. Процедуры проводятся в целях обеспечения целевой деятельности и осуществляются добровольно в отличие от административных и уголовных производств. У сотрудников организации нет права проводить личный досмотр, однако сотрудники также не могут предоставить специфическую услугу в случае отказа от прохождения «гражданского досмотра», который заключается в бесконтактной проверке субъекта особых общественных отношений.

Правопорядок в период проведения ЕГЭ обеспечивают сотрудники полиции. Они проверяют всех участников ЕГЭ с помощью специального оборудования с целью выявления запрещенных предметов. При сдаче ЕГЭ школьники проходят через металлоискатель. Если последний срабатывает, учащемуся предлагается достать металлический предмет и пройти снова. Полицейские могут осуществлять досмотр ручным металлоискателем поверх одежды. Если обучающийся отказывается от процедур, он не допускается к сдаче экзамена. Таким образом, здесь также действует схема гражданского контракта - принимай условия или не пользуйся.

Подобную схему социального соглашения реализуют также те школы, которые заключают с родителями договор об условиях обучения в школе, одно из положений которого заключается в том, что ученик обязан сдавать мобильное устройство перед 
началом занятий. В этом случае школа несет материальную ответственность за их сохранность и обязана оборудовать места для хранения ценных вещей.

Менее обременительный устав означает выбор умеренной модели, когда ответственность за сохранность гаджета лежит только на его владельце (родителях, законных представителях владельца). Ограничения в этом случае носят в основном декларативный характер, а возможности по административному воздействию минимальны. После отказа пользователя выполнять условия пользования мобильным устройством делается запись о замечании в дневнике обучающегося, он вызывается для беседы с куратором, ставятся в известность родители. За неоднократное нарушение, оформленное докладной на имя директора, проводится разъяснительная беседа с обучающимися в присутствии родителей. При повторных фактах нарушения ученик предоставляет объяснительную записку, ему объявляется выговор, а мобильное устройство передается на ответственное хранение в канцелярию, а затем родителям обучающегося; проводится собеседование с администрацией школы. Самое большое наказание в этой пермиссивной модели - это запрет ношения сотового телефона на весь учебный год, накладываемый комиссией по урегулированию споров между участниками образовательных отношений.

Высшие учебные заведения пользуются такими же правовыми инструментами, что и школы, а именно локальными актами.

\section{ГАДЖЕТЫ И КУРСАНТЫ}

Проблема ограничения обучающихся в пользовании персональными мобильными устройствами особенно актуальна для ведомственных вузов Министерства обороны, Министерства внутренних дел, Федеральной службы безопасности, Федеральной службы исполнения наказаний.

Руководители стремятся исключить нарушения режима секретности, защитить репутацию учреждения, предотвратить использование средств связи для нарушения служебной дисциплины. Существенно, что у командного состава есть право по внутреннему уставу досматривать личные вещи и изымать их, например ноутбук или смартфон.

Мобильные устройства с учетом их современных возможностей служат угрозой сохранности государственной тайны и сведений, содержащих эту тайну. В связи с этим использование персональных смарт-устройств на территории мест прохождения военной службы, в ведомственных вузах подвергается ограничению.

Накоплена судебная практика в отношении курсантов ведомственных вузов, где ответчиком выступает образовательная организация, истцом - отчисленный обучающийся, а в деле фигурируют действия, связанные с использованием мобильного устройства.

Рассмотрим первый кейс из г. Белгорода «Хоменок против БелЮИ МВА России». В 2013 г. истец М. А. Хоменок, бывший курсант Белгородского юридического института МВА России, обратился в суд с иском о признании незаконным приказа об отчислении и увольнении из органов внутренних дел, об аннулировании записи об увольнении в трудовой книжке, восстановлении на службе в должности слушателя. Октябрьский суд г. Белгорода рассмотрел его дело и признал правомерным отчисление из института и увольнение истца из органов внутренних дел в связи с совершением проступка, порочащего честь сотрудника OBA, а именно размещением в социальных сетях информации с использованием нецензурных выражений и изображений, нарушаю- 
щих нормы морали. Обоснованными признаны доводы представителей ответчика, что указанные действия истца создают условия для формирования негативного образа сотрудника органов внутренних дел. В рассмотренных судом материалах имелся скриншот записи, содержащий прямую негативную оценку группы лиц по признакам национальности и происхождения ${ }^{4}$.

Рассмотрим второй кейс «Артюшин против ВЮИ ФСИН России». Бывший курсант В. А. Артюшин в 2014 г. обратился в суд с иском против Владимирского юридического института ФСИН России о признании незаконным приказа об отчислении из института, а также дисциплинарного взыскания в виде отчисления - как не соответствующих тяжести совершенного проступка, о восстановлении на обучении как курсанта. Фрунзенский суд г. Владимира подтвердил, что действия истца по участию в распространении информации в сети Интернет, порочащей звание сотрудников правоохранительных органов, оскорбляющей сотрудника ВЮИ ФСИН России, наносят ущерб авторитету учреждения уголовно-исполнительной системы, что правомерно повлекло привлечение к дисциплинарной ответственности. В рамках проведенной служебной проверки действия А. были признаны как противоречащие служебной и профессиональной этике поведения сотрудника уголовно-исполнительной системы.

Таким образом, суд отказался признать приказ об отчислении из института незаконным, согласившись с тем, что по результатам служебной проверки имелись основания для привлечения сотрудника к дисциплинарной ответственности. При этом право выбора конкретного вида дисциплинарной ответственности отнесено к полномочиям начальника института, а служебная проверка признана произведенной с учетом обстоятельств дисциплинарного проступка и личности сотрудника5.

Практика показывает, что суды редко принимают решения в пользу отчисленных обучающихся, которые обращаются с иском о восстановлении, так как дисциплинарное взыскание накладывается после тщательной комплексной служебной проверки, для проведения которой у ведомственной образовательной организации есть все ресурсы.

\section{ЗАКАЮЧЕНИЕ}

В статье были обозначены актуальные проблемы регулирования использования мобильных устройств в образовательных организациях России. Произведена оценка данной темы как неоднозначной, мало разработанной, открытой для юридических новелл и технологических решений.

Руководство образовательных организаций вправе устанавливать требования по отношению к использованию персональных гаджетов в служебной деятельности через издание нормативных правовых актов. Каждая организация выпускает локальный акт, в который включает само распоряжение, особенности действия приказа, ответственного за исполнение. После того как все участники юридического соглашения ознакомлены с локальным актом под роспись, они несут в дальнейшем ответственность за его исполнение. В случае нарушения руководитель имеет право на дисциплинарное наказание провинившегося начиная от замечания и до увольнения в случае неоднократного пренебрежения приказом.

Сотрудник организации и обучающийся добровольно принимают на себя обязательства по выполнению соответствующего приказа, временно отчуждая долю личной свободы для получения иных социальных благ в виде образования, карьерного роста и последующего материального достатка. 
Можно прогнозировать рост корпоративного тренда в отношении защиты деловой репутации организации. Вероятно, в будущем обучающие и обучаемые должны будут проходить курсы медиаграмотности, где будут такие разделы, как «прозрачность и цифровой след», «этика интернет-коммуникаций», «защита от цифрового хулиганства», «безопасный интернет», «медиакритика».

В свою очередь, можно предположить, что в условиях усиления борьбы между личным и частным правом в будущем финансово-правовые возможности образовательных организаций будут расширены, и они смогут пользоваться глушителем радиочастот, привлекать специальный персонал для обыска обучающихся, активно использовать металлодетекторы. На каждое технически продвинутое решение со временем приходит административная резолюция. Средства подавления связи тоже совершенствуются. Если сейчас джаммеры имеют ограничения по точечному глушению сигналов, то в будущем этот вопрос техники может быть решен, и образовательные организации получат больше возможностей для их использования.

С другой стороны, следует признать справедливым нарекание со стороны обучающихся, что в случае необходимости использования технических устройств, в том числе мобильных, для целей обучения образовательная организация обязана обеспечить доступ к Интернету.

Обучение работе не только со стационарными устройствами, но и с мобильными образовательными приложениями становится одной из компетенций. Особенно остро вопрос с доступностью образовательных ресурсов встал в условиях дистанционного обучения в апреле 2020 г., когда сотни тысяч обучающихся пытаются выполнить задания на порталах «Якласс», «Учи.ру», «Российская электронная школа», они дают сбой. Урок на платформе «Зум» превращается в разбор причин невозможности зайти, отсутствия звука.

Особенно остро этот вопрос стоит в юридических ведомственных вузах, где обучающимся нужен доступ к новеллам юриспруденции и юридической практике, но при этом запрещается пользоваться персональным электронными устройствами.

Возможность использовать глобальные информационные ресурсы является сегодня одним из признаков технической оснащенности образовательного процесса. Может возникнуть вопрос: если задачи образования включают изучение различных электронных публикаций, то каким образом они могут решаться мобильными устройствами? Не компьютерами, которые фактически есть уже в каждой школе, в каждом вузе, а именно мобильными устройствами, которые являются предметом данного обсуждения? Аело в том, что именно смартфоны существенно расширили интернетдоступ для тех, кто не имеет персонального компьютера, особенно в странах Азии и Аатинской Америки. Основатель Фейсбука М. Цукерберг ставил амбициозную цель охватить всех землян глобальной сетью, рассчитывая именно на относительно дешевое средство доступа - смартфоны. В ведомственных вузах только $30 \%$ курсантов имеют ноутбуки, так как их негде хранить и трудно обеспечить их сохранность. Однако все курсанты имеют смартфоны, которые тем не менее не везде разрешены к использованию.

Поэтому компромиссное разрешение спора между свободой и ограничением мобильных устройств может заключаться в предоставлении доступа к образовательным ресурсам самой организацией. Будем исходить не из логики дихотомии «или смартфон - или вуз», а из логики дополнения - «и высшее образование, и техническое перевооружение». Игнорирование технических новинок в образовательных организа- 
циях означает отставание от модернизации. Однако навязчивые привычки, мешающие процессу обучения, и попытки недобросовестного использования гаджетов - это то, с чем образовательные организации не могут мириться.

\section{ПРИМЕЧАНИЯ}

1 Согомонян А. Экзамен не сдан: за что могут аннулировать результаты EГЭ? URL: http://www.garant.ru/article/1122670/ (дата обращения: 10.10.2019).

2 Воздушный кодекс Российской Федерации от 19 марта 1997 г. №60-Ф3 (ред. от 03.08.2018) (с изм. и доп., вступ. в силу с 14 августа 2018 г.). URL: http://www.consultant.ru/document/cons_ doc_LAW_13744/(дата обращения: 10.10.2019).

$\overline{3}$ Указ Президента РФ от 31 марта 2010 г. № 403 «О создании комплексной системы обеспечения безопасности на транспорте». URL: http://www.consultant.ru/document/cons_doc_LAW_ 99034/ (дата обращения: 10.10.2019).

${ }^{4}$ Решение по делу №2-2129-2013г. от 30 мая 2013 г. // Судебные и нормативные акты РФ. URL: http://sudact.ru/regular/doc/vCqxFju4KhoO/ (дата обращения: 11.10.2019).

5 Решение № M-97/2014 2-374/14 2-374/2014 M-97/2014 2-374/2014 от 24 марта 2014 г. // Судебные и нормативные акты PФ. URL: http://sudact.ru/regular/doc/q9WWQssD9F5r/ (дата обращения: 11.10 .2019$)$.

\section{СПИСОК АИТЕРАТУРЫ}

Бозаджиев, В. А. (2018) Гаджет-аддикции: психологический аспект // Современный ребенок: какой он? : материалы всероссийского научно-педагогического форума / сост. С. В. Портье, А. Ю. Манекина, С. В. Мачинская, Т. В. Абрамова, А. В. Корнилова. Челябинск : УМЦ. 196 с. C. $170-181$.

Викторова, О. В. (2017) Социологический анализ аддикций: гаджет-зависимость как вид нехимической зависимости // Теоретические и практические аспекты развития научной мысли в современном мире : сборник статей Международной научно-практической конференции : в 2 ч. / отв. ред. А. А. Сукиасян. Уфа : Аэтерна. Ч. 2.298 с. С. 256-262.

Николаев, С. Р., Волкова Т. Г. (2013) Аинамика эмоционально-психологических состояний студентов при гаджет-аддикции // Труды молодых ученых Алтайского государственного университета. № 10. С. 370-372.

Тимощук, А. С. (2018) Клиповое мышление как феномен социотехнической среды // Тенденции и перспективы развития социотехнической среды : материалы IV международной научно-практической конференции, Москва, 13 декабря 2018 г. / отв. ред. И. А. Сурат. М. : ИзА-во СГУ. 669 с. С. $462-474$.

Хатмуллина, А. И. (2019) Гаджет-зависимость детей - проблема ХХІ века // Человек. Общество. Культура. Социализация : материалы XV Международной молодежной научно-практической конференции : в 3 ч. / отв. ред. В. А. Бенин. Уфа : БГПУ. Ч. 1.375 с. С. 308-313.

Aата поступления: 11.10.2019 г

\section{PRACTICES RESTRICTING THE USE OF GADGETS IN EDUCATIONAL INSTITUTIONS}

\section{A. S. TIMOSHCHUK}

FPS VLADIMIR LAW INSTITUTE

Digitalization and mediatization have a twofold effect. They enhance inclusion, increase eventuality, and accelerate procedurality. Digital technology, on the other hand, provides unprecedented opportunities for the anonymization of evil and the manipulation of public consciousness. The paper is dedicated to the issue of students using gadgets when they are in educational institutions of Russia.

The author considers the case law dealing with cadets of departmental universities where the defendant is the educational organization and the plaintiff is the expelled student, and the case involves actions related to the use of a mobile device. 
Key words: digital society; information security; ICT competence; informatization; digitalization of education; gadget addiction; jammers; freedom to disconnect; digital silence; sovereign cognition

\section{REFERENCES}

Bozadzhiev, V. L. (2018) Gadzhet-addiktsii: psikhologicheskii aspekt. In: Sovremennyi rebenok: kakoi on? : materialy vserossiiskogo nauchno-pedagogicheskogo foruma / comp. by S. V. Port'e, L. Yu. Manekina, S. V. Machinskaia, T. V. Abramova and L. V. Kornilova. Cheliabinsk, UMTs. 196 p. Pp. 170-181. (In Russ.).

Viktorova, O. V. (2017) Sotsiologicheskii analiz addiktsii: gadzhet-zavisimost' kak vid nekhimicheskoi zavisimosti. In: Teoreticheskie $i$ prakticheskie aspekty razvitiia nauchnoi mysli v sovremennom mire : sbornik statei Mezhdunarodnoi nauchno-prakticheskoi konferentsii : in 2 parts / ed. by A. A. Sukiasian. Ufa, Aeterna. Part 2. 298 p. Pp. 256-262. (In Russ.).

Nikolaev, S. R., Volkova T. G. (2013) Dinamika emotsional'no-psikhologicheskikh sostoianii studentov pri gadzhet-addiktsii. Trudy molodykb uchenykb Altaiskogo gosudarstvennogo universiteta, no. 10, pp. 370-372. (In Russ.).

Timoshchuk, A. S. (2018) Klipovoe myshlenie kak fenomen sotsiotekhnicheskoi sredy. In: Tendentsii i perspektivy razvitiia sotsiotekbnicheskoi sredy : materialy IV mezhdunarodnoi nauchno-prakticheskoi konferentsii, Moskva, 13 dekabria 2018 g. / ed. by I. L. Surat. Moscow, Izd-vo SGU. 669 p. Pp. 462-474. (In Russ.).

Khatmullina, A. I. (2019) Gadzhet-zavisimost' detei - problema KhKhI veka. In: Chelovek. Obshchestvo. Kul'tura. Sotsializatsiia : materialy XV Mezhdunarodnoi molodezhnoi nauchno-prakticheskoi konferentsii : in 3 vol./ ed. by V. L. Benin. Ufa, BGPU. Vol. 1. 375 p. Pp. 308-313. (In Russ.).

Submission date: 11.10.2019.

Тимощук Алексей Станиславович - доктор философских наук, доцент, профессор кафедры гуманитарных и социально-экономических дисциплин Владимирского юридического института ФСИН России. Адрес: 600020, Россия, г. Владимир, ул. Б. Нижегородская, д. 67-е. Тел.: +7 (4922) 45-44-75. Эл. аapec: human@vui.vladnfo.ru

Timoshchuk Aleksey Stanislavovich, Doctor of Philosophy, Associate Professor, Professor, Department of the Humanities and Socio-Economic Disciplines, Vladimir Law Institute, Federal Penitentiary Service of Russia. Postal address: 67-e, B. Nizhegorodskaya St., Vladimir, Russian Federation, 600020. Tel.: +7 (4922) 45-44-75. E-mail: human@vui.vladnfo.ru 